\title{
Sports InJuries Sustained at THE SiXth All Africa Games: The Physiotherapy Perspective
}

\begin{abstract}
The Sixth All Africa Games were held in Zimbabwe in September 1995. A voluntary physiotherapy service was provided to guest athletes. Data was gathered relating to onset, mechanism, region and management of injuries. During the 10-day period of the games, 541 treatments were performed on 258 guest athletes. The onset of injury in $35.3 \%$ of cases was prior to the start of the games. Overuse was the most common mechanism of injury and $24 \%$ of injuries were in the chronic stage. The lower limb was the site of $49.5 \%$ of injuries
\end{abstract}

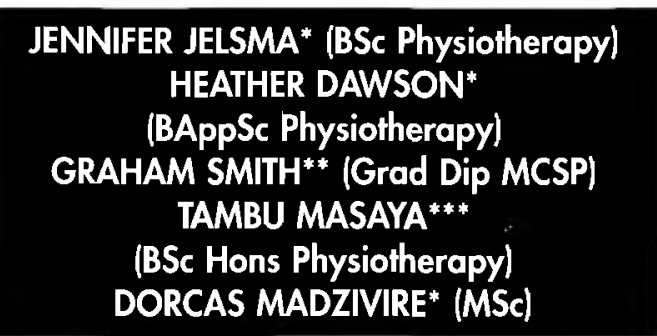
with strains and sprains contributing 75\% of the injuries in this study. All together 16 treatment modalities were used, the most frequently used being ice combined with compression. Sixty-two per cent of athletes attended for a single treatment.

The mechanisms, distribution and types of injuries were similar to those described by other authors. Of relevance is the number of athletes who were carrying the injury at the commencement of the games and that the main mechanism of injury was overuse. This has implications for training and treatment. The need to provide a comprehensive first treatment with advice regarding ongoing self management was essential as the majority attended only once.

\section{KEY WORDS: MULTI-SPORT, EPIDEMIOLOGY OF SPORTS INJURIES, PHYSIOTHERAPY}

\author{
* Department of Rehabilitation, University of Zimbabwe, Box A178, Avondale, Harare, Zimbabwe. \\ Tel: $2634791631 \times 175(\mathrm{~W}) ; 2634302406(\mathrm{H})$. \\ ** PhysioTech, Glasgow, Scotland. \\ *** Harare Central Hospital. Correspondence to first author.
}

\section{INTRODUCTION}

In recent years there has been a growing awareness of the need to promote safe and successful competition by documenting the epidemiology of injuries sustained at large multi-sport events. ${ }^{1}$ The injury experiences from a medical perspective have been recorded for several sporting events ${ }^{1234}$ but there is a paucity of literature to guide physiotherapists in the preparation and planning of specific physiotherapy services at such events. Exceptions include physiotherapy specific articles on the patterns of injury and treatment modalities at the 1991 World Student Games in Sheffield $^{56}$ and the XII Commonwealth Games held in Brisbane.

The All Africa Games (AAG) is the third largest multi-sport event after the Olympic Games and the Commonwealth Games. The Sixth AAG was held in Zimbabwe in September 1995 and involved 3188 competitors, 2232 male and 956 female, from fifty countries participating in 21 sports. A voluntary physiotherapy service was provided to both local teams and guest athletes by 40 of the 120 members of the Zimbabwe Physiotherapy Association. Each Zimbabwean team was allocated a physiotherapist and guest athletes were catered for both at the venues and at the Games Village Facilities in the two cities that were host to the AAG. This paper serves to document the most common injuries encountered and the methods of intervention employed by the host physiotherapists who provided treatment to the guest athletes. It is intended that such information will prove useful for any physiotherapy body that undertakes to provide treatment as a host nation to guest athletes. Physiotherapy services provided to the Zimbabwean team were analysed separately and will be presented elsewhere. Similarly no data is presented on athletes from the teams of countries who had their own physiotherapists.

\section{SUBJECTS AND METHODOLOGY}

Physiotherapy was provided free of charge within the Games Villages from 7 h00 to 19 h00. The presence of the physiotherapists was well advertised and the venues were easily accessible.

The vast majority of cases were selfreferred and each athlete who presented for physiotherapy was assessed and the findings and treatment documented. A separate sports massage service was provided but as clients who used this service were not injured, their data is not included in this analysis. A summary of the findings and intervention was then recorded on a separate spreadsheet. This questionnaire (Figure 5,6) was developed specifically to record physiotherapy data and was based on the general medical data collection forms used during the 1994 Commonwealth Games in Victoria, Canada and the World Police and Fire Games held in Melbourne in 1995. Information was gathered regarding demographic details, sport type, position, history of injury, region and structure injured, presenting problems, physiotherapy intervention and advice given regarding return to sport. The history of injury included time of onset, mechanism and classification regarding stage of injury, i.e. acute (less than 36 
hours), subacute or chronic/overuse.

On completion of the games, the data was analysed using descriptive statistics by the SPSS-PC statistical package.

\section{RESIILTS}

During the ten-day period of the games, 1141 treatments were carried out on 520 athletes by the Village, Zimbabwe Team and Venue physiotherapists. A total of 541 treatments was provided for 258 guest athletes (213 in the Village facilities and 45 at the Venues). There were 201 males and 57 females (a ratio of 78:22 compared to $70: 30$ of all participating athletes). The median age was 24 years and the range was 14 to 58 years. A t-test suggested a significant difference ( $\mathrm{p} .=0.01)$ between the ages of the males (mean=25.6 $\mathrm{SD}=6.8$ ) and females (mean $=23.4, \mathrm{SD}=4.6$ ). Athletes from 38 different countries were seen with $66.6 \%$ deriving from nonAnglophone countries.

Figure 1 depicts the numbers of injured athletes who participated in the different sports grouped according to gender. Twelve clients who presented for treatment were noncompetitors. Track athletics had the highest number of injuries for both males (51) and females (16). Track athletes represented $22 \%$ of all competitors in the AAG and $28.7 \%$ of injured athletes were drawn from these events. Male martial arts participants similarly accounted for a higher proportion of injured clients (19\%) than proportion of registrants for the Games (13\%). Competitors in these disciplines martial arts, which included judo, karate and Tae Kwon Do, comprised the next largest group of male clients (39) seeking physiotherapy attention. Hockey players accounted for the largest female group (12). Other sports that accounted for ten or more injuries in males were handball, weightlifting, wrestling, volleyball and swimming and diving.

Ninety-one athletes $(35 \%)$ reported the onset of injury as being prior to the start of the Games, $38(14.7 \%)$ were injured in training and $88(34 \%)$ were injured during the rounds and finals of competition. The remainder were injured in nonsport situations or postcompetition. Most of the injuries, 106 (41\%), were treated in the acute stage, followed by $63(24 \%)$ in the chronic stage. The mechanisms of injury and onset of injury are shown in Figure 2. The most common mechanism was overuse as reported in $58(22.5 \%)$ cases. Contact with a per-
SPORT TYPE

ATHLETICS TRACK JUDO/MARTIAL ARTS

HANDBALL

VOLLEY BALL

SWIMMING/DIVING

WRESTLING

WEIGHTLIFTING

FOOTBALL

CYCLING

BOXING

TENNIS

TABLE TENNIS

BASKETBALL/NETBALL

ATHLETICS FIELD

SHOTTISTS

GYMNASTICS

HOCKEY

NON-ATHLETES

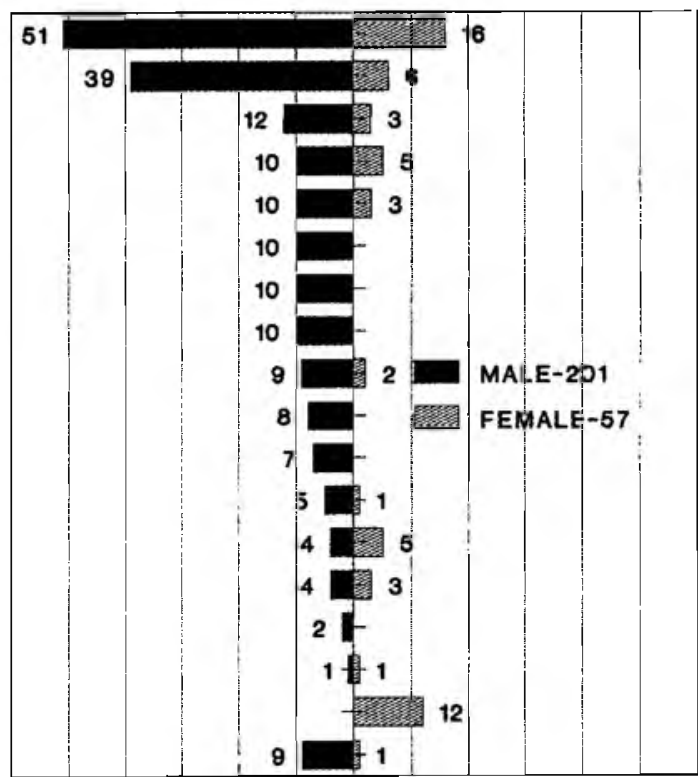

FIGURE 1:

The number of injured athletes per sport, grouped according to gender. $N=258.201$ males, 57 females.

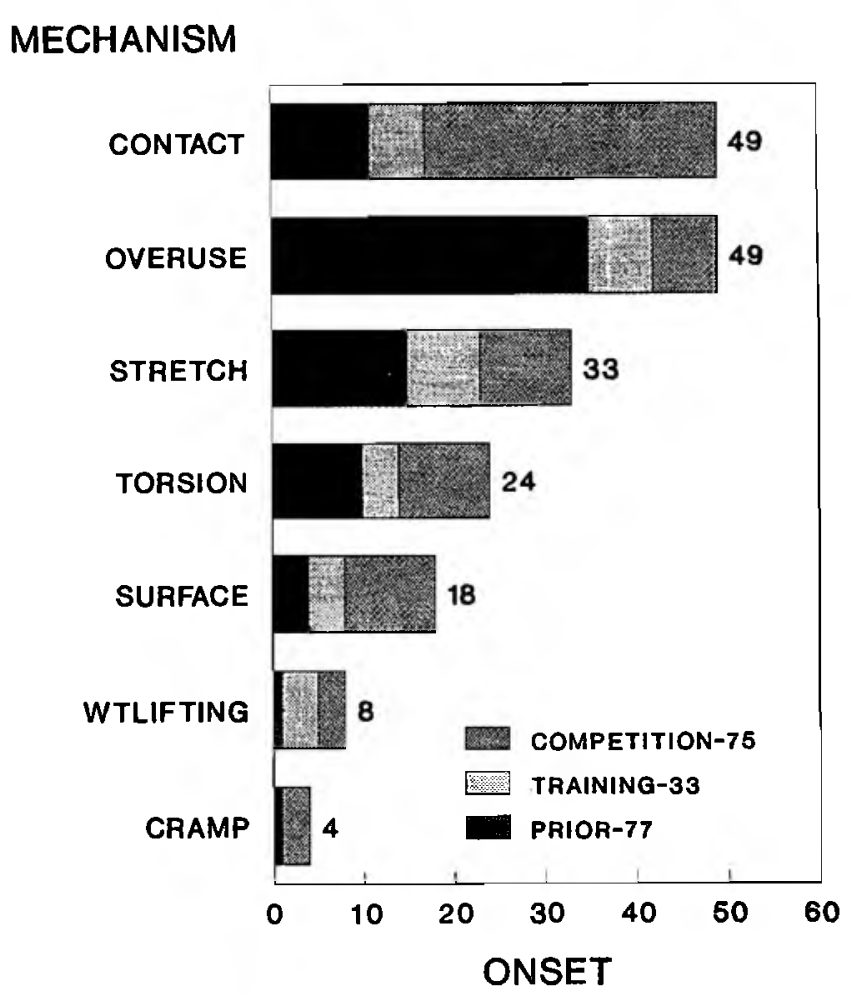

FIGURE 2:

Mechanisms of injury grouped according to time of onset of injury. Contact includes contact with a person or a tool. $N=185$. Non-sport injuries and missing data account for a further 73 cases. 


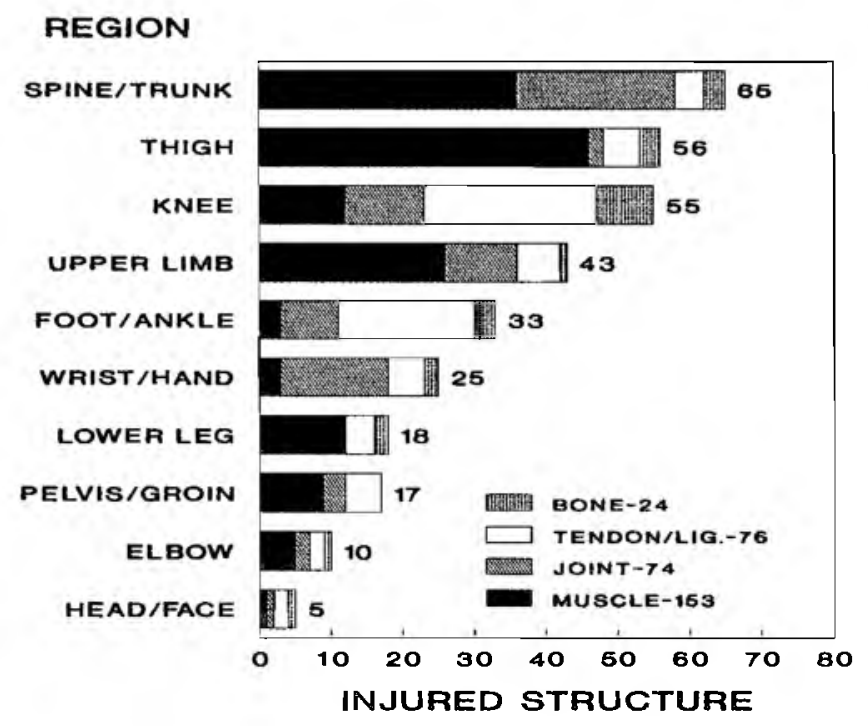

FIGURE 3:

Injured regions and structures. $N=327$ injured structures in 258 athletes. Lig.=ligament.

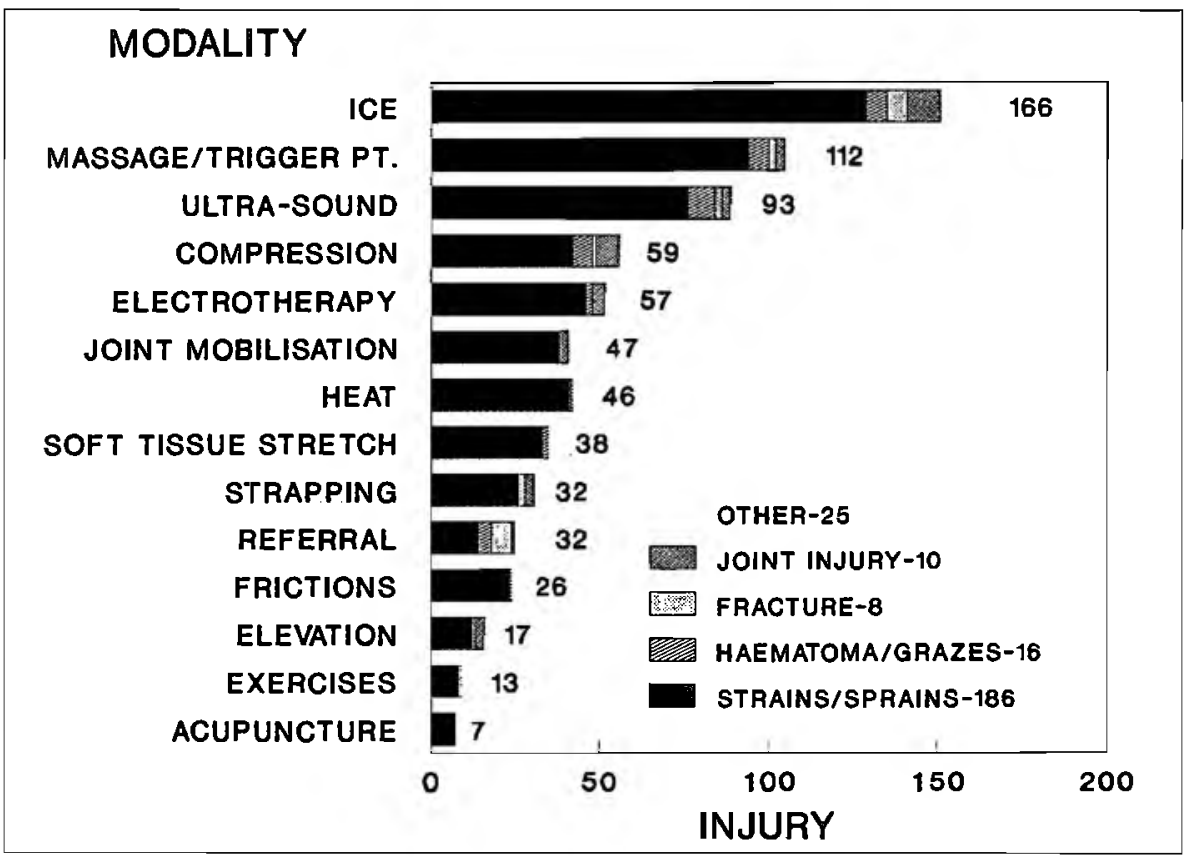

FIGURE 4:

Modalities of treatment. $N=745$ applications of modalities in 246 athletes. Data on 12 cases were missing. Joint injury included dislocation, subluxation and effusion. Others included cramp, nerve compression, vascular damage, retropatellar pain and "shin splints".

son was cited as the mechanism of injury in $48(18.6 \%)$ and stretch in $38(14.7 \%)$ cases.

The 258 athletes presented with a total of 310 injured regions of the body and 341 injured structures (Figure 3 ). The lower limb was the site of $153(49.5 \%$ of regions) injuries with the most frequently injured regions being the knee ( $14.5 \%$ of cases) and thigh (17.1\%). In the upper limb the shoulder was most often injured no other injury (eg. haematoma, fractures, subluxations) contributing more than $5 \%$ to the total.

There were 745 applications of treatment modalities on the injuries sustained (Figure 4). Ice was the most frequently used modality followed by therapeutic and trigger point massage and ultrasound. The mean number of modalities per athlete was 2.7. Thirty-two cases $(12.4 \%)$ were referred to medical services for $\mathrm{X}$-rays or medical treatment requiring medication. The total number of treatments given was 520 and the mean number per client was 2.27. Females attended more frequently (mean $=2.85, \quad \mathrm{SD}=2.39$ ) than males (mean=2.08, SD=2.04) (p.=.017). One hundred and fifty-nine athletes $(61.9 \%)$ attended a single session of physiotherapy and $83.7 \%$ attended less than three times.

Seventy-six athletes (29.5\%) were judged to have sustained an injury severe enough to warrant advice either to rest from sporting activity and not compete (regarded as a severe injury) or to modify training (moderately severe injury). Athletes advised to return to full activity were regarded as having minor injuries.

\section{DISCUSSION}

As in the other studies ${ }^{5.7}$ it was difficult to collect data from teams that had their own physiotherapists and the information presented relates predominantly to guest athletes from the smaller national teams. Those teams accompanied by their own physiotherapist, (such as Kenya and South Africa) scarcely used the Village services. The data presented here is consequently not necessarily representative of the injuries sustained by all the participants, but the results are of relevance, for any host country planning to provide physiotherapy services for guest athletes.

As $66.6 \%$ of the clients came from non-Anglophone countries, communication with clients was limited and made history taking and treatment interaction difficult. Accessibility to professional interpreters is essential to facilitate safe and effective treatment. The smaller number of injured female patients was expected but the fact that the proportion was smaller than the proportion of female athletes registered for the AAG might reflect that female events give rise to fewer injuries. Female athletes were significantly younger and attended more 
treatment sessions. It is unclear if the increased number of attendances reflected greater severity of injury or other factors.

The most striking feature of the findings on mechanisms, distributions and types of injuries is the similarity to those published regarding other major multisport events. ${ }^{13.7}$ This is of interest because most of AAG participants seen in this study were from developing countries where training and medical resources may be less than optimal. The percentage of injured track athletes presenting to the Village Facilities was both absolutely and proportionately (when compared to total AAG registrants for these events) much larger than from any other sport. The larger representation of these events is similar to other studies. ${ }^{13.8}$ Martial arts also accounted for a higher proportion of injuries than the proportion registered and clients from these disciplines required the greatest number of referrals to medical services. This would lend support to the suggestion of Martin et al 1985 suggestion that medical care resources should be specifically allocated to these disciplines.

It is noteworthy that $35.3 \%$ of the athletes were carrying the injury at the opening of the AAG. The ongoing nature of the injuries was reinforced by the findings that $24 \%$ of the injuries were in the chronic stage and that the cause of injury was identified as overuse in $22.5 \%$ of the athletes. This high rate of pre-existing injury is almost universally reported in the literature. Hannay et al 1993 found $40 \%$ of injuries had started before the World Student Games in Sheffield, Jull and Cupit (1984) report that $50 \%$ of injuries seen at the XII Commonwealth Games were not acute but "more long term injuries" and Martin et al (1985) found that $26 \%$ injuries were sustained prior to the 1985 Junior Olympics. Several other factors may contribute to the high rate of preexisting and training injury found. Athletes may deny injury in order to compete. There may be excessive pressure on athletes to compete and represent their countries. The intensive training in preparation for high profile events may exacerbate pre-existing conditions and precipitate new injuries. Health professionals and coaches need to be aware of these factors and adopt suitable strategies to allow for physiotherapy involvement during pre-event training. There is an obvious need for improved screening before participation in international events so the health professions and coaches are aware of these problems and can adopt suitable strategies. The need for both improved training methods and ongoing involvement of physiotherapists is underscored.

As in previous studies, most of the injuries were to the lower limb and soft tissue structures (muscles and ligaments). ${ }^{1.3}$ The knee and thigh are consistently reported as the most vulnerable sites of injury. ${ }^{7}$ In this study, as in other studies, sprains and strains were the most common cause of injury. ${ }^{1,3.8}$

The participation of physiotherapists at the AAG and at the XII Common- wealth Games is reflected by the greater variety of modalities used at these events (17 and 16 respectively) compared to most other studies. Ice application remained the mainstay of treatment and was applied to $65.5 \%$ of clients. Usually the ice was applied through the medium of Cryocuff ${ }^{\circledR}$ which combines cold and compression. This figure is comparable to those reported at the 1995 Junior Olympics $(60 \%)$ but considerably more than the $32.5 \%$ usage of ice reported during the XII Commonwealth Games. Modified trigger point massage, i.e. the application of sustained and gradually increasing pressure over painful sites of localised muscle spasm as described by

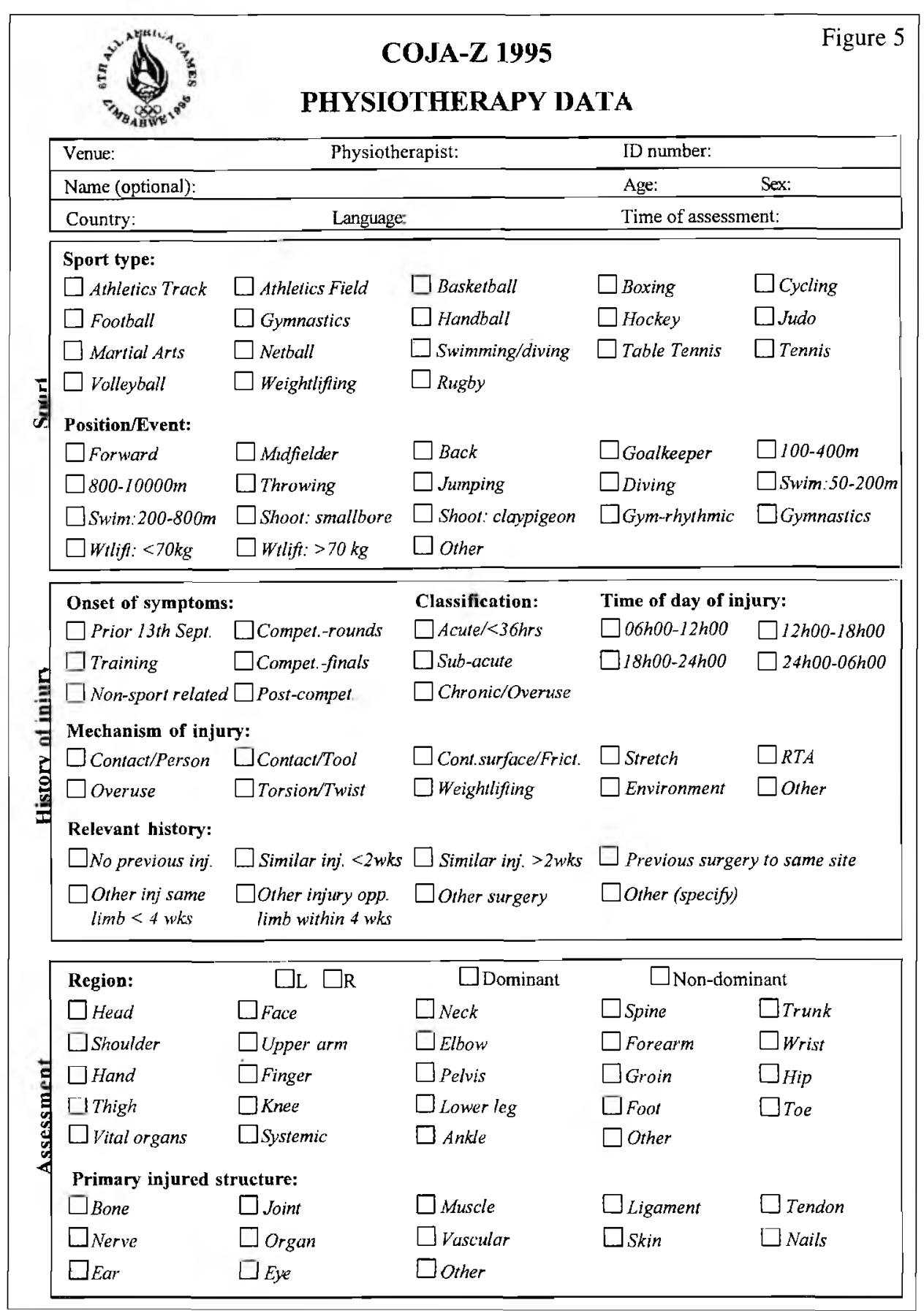


Manheim and Lavett (1989), was frequently combined with other massage techniques. Electrotherapy modalities, which included ultra-sound therapy, interferential, laser and TENS, represented $20 \%$ of modalities applied, a figure that is lower than that reported by Jull and Cupit (1984) at the XII Commonwealth Games. A decision was taken to limit the use of electrotherapy modalities to clients with whom adequate communication was possible.

No other article has documented the mean number of treatment sessions per athlete and in this study it was found to be relatively low (2.27) with $61.9 \%$ attending only once. Several hypotheses are postulated to explain this phenome- non. As the severity of injury prevented or limited participation in only one third of cases, it is possible that other athletes did not feel that their injuries were severe enough to warrant continuing treatment. Many athletes attended just prior to participation and it is likely that they were seeking reassurance as to their fitness to compete. They then defaulted on failing to qualify or on conclusion of competition. The low attendance rate was similar at both Village facilities.

The results presented in this article are intended to provide guidelines to physiotherapists in a host country as to the type of injuries sustained by visiting athletes that are likely to need management. Patterns of injury were similar to those

Figure 6

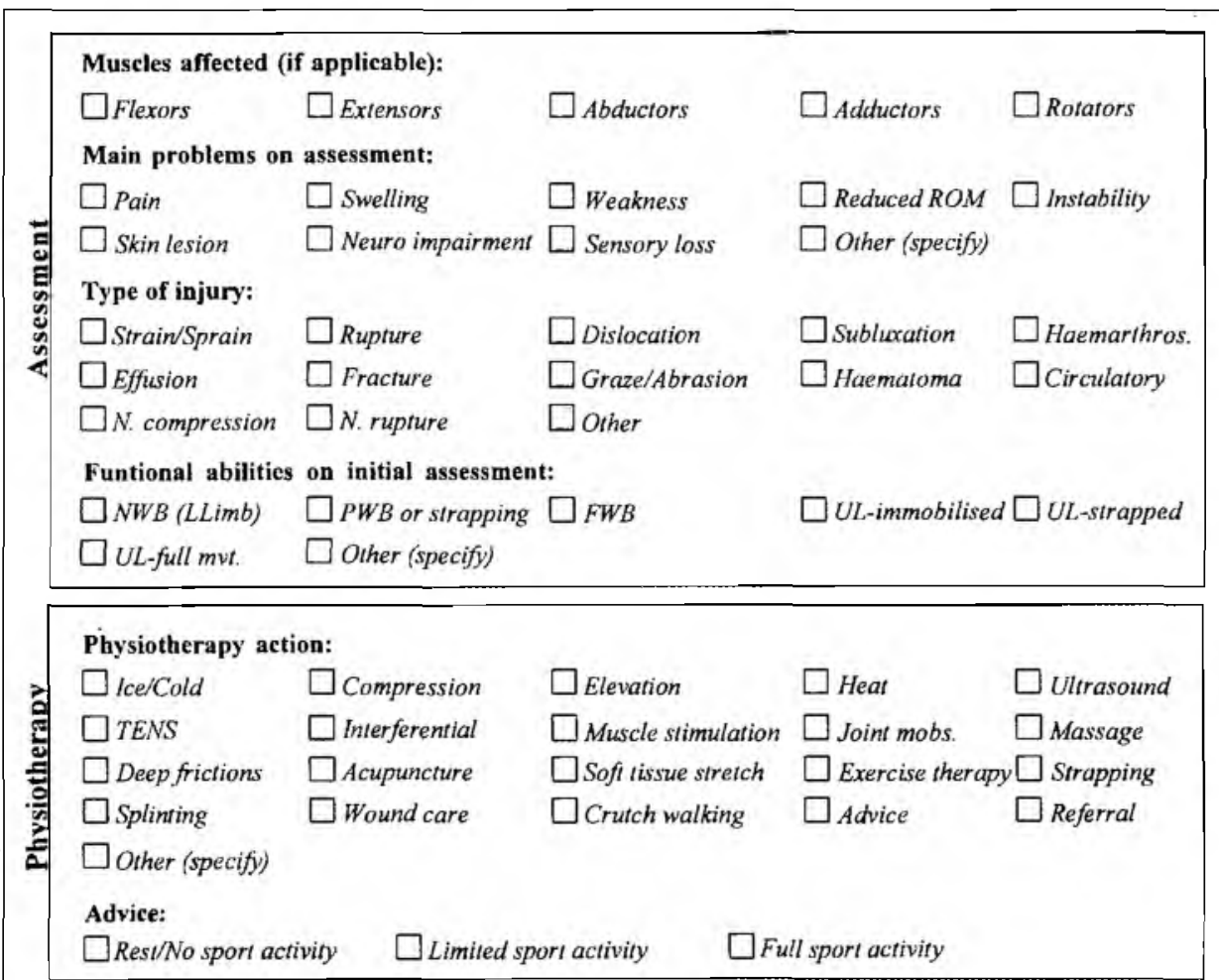

\begin{tabular}{l}
\hline TO BE FILLED IN AFTER LAST ATTENDANCE: \\
Funtional abilities on final assessment: \\
$\square$ NWB (LLimb) $\quad \square$ PWB (supported) $\quad \square$ FWB \\
$\square$ UL-full mvt. $\quad \square$ Other (specify) \\
Return to sport: \\
$\square$ Cannot compete $\square$ Can compete $\quad \square$ Other (specify) \\
Mode of disposal: \\
$\square$ Referred $\quad \square$ Discharged $\quad \square$ Defaulted $\quad \square$ End of Games $\square$ Other \\
Days from first examination to last attendance: \\
Number of physiotherapy treatments:
\end{tabular}

Comments:

previously documented, despite the difference in the participating population. As ice, the Cryocuff ${ }^{\circledR}$ and ultra-sound were frequently used, it is suggested that this equipment be made available to physiotherapists called upon to provide services at multi-sport events. It is strongly recommended that the collection of epidemiological data be standardised at multi-sport events to allow for comparison between these events.

\section{ACKNOWLEDGEMENTS}

COJA-Z, the organising committee of the AAG; Cletus Satumba for assistance with data collection.

\section{REFERENCES}

1. Martin RK, Yesalis CE, Foster D and Albright JP. Sports injuries at the 1985 Junior Olympics: An epidemiological analysis. Am J Sports Med 1987; 15: 603608.

2. Peres-Perdomo R, Morell-Rivera CA, Mayor-Becerra AM, Serrano-Rodriguez RA and Frontera WR. Description of morbidity notified to the epidemiologic surveillance system of the XVII Central American and Caribbean Games, Puerto Rico 1993. Puerto Rico Health Sciences Journal 1994; 13: 267-272.

3. Laskowski ER, Najarian MM, Smith AM, Stuart MJ and Friend LJ. Medical coverage for multi-event sports competition: A comprehensive analysis of injuries in the 1994 Star of the North Summer Games. Mayo Clin Proc 1995; 70: 549555.

4. Ahuja A and Ghosh AK. Pre-Asiad ' 82 injuries in elite Indian athletes. $\mathrm{Br} J$ Sports Med 1985; 19: 24-26

5. Hannay DR, English BK, Usherwood TP and Platts M. The provision and use of medical services during the 1991 World Student Games in Sheffield. I Public Health Med 1993; 15: 229-234.

6. Thompson S and Ratcliffe A. World Student Games, 1991-Sheffield. Experiences of student physiotherapists. Physiotherapy 1991; 77: 820.

7. Jull GA and Cupit RN. Physiotherapy at the XII Commonwealth Games: Organisation and utilisation of services. Aust J Physiotherapy 1984; 30: 3-14_

8. Watson AWS. Incidence and nature of sports injuries in Ireland. Am J Sports Med 1993; 21: 137-143.

9. Manheim $\mathrm{CJ}$ and Lavett $\mathrm{D}$. The Miofascial Release Manual. Canada: Slack Incorporated, 1989. 